\title{
Detecting mRNA Predictors of Acetaminophen-Induced Hepatotoxicity in Mouse Blood Using Quantitative Real-Time PCR
}

\author{
Syu-ichi Kanno,* Ayako Tomizawa, and Shin Yomogida \\ Department of Clinical Pharmacotherapeutics, Tohoku Pharmaceutical University; 4-4-1 Komatsushima, Aoba-ku, \\ Sendai 981-8558, Japan. \\ Received September 24, 2015; accepted December 11, 2015; advance publication released online December 25, 2015
}

\begin{abstract}
Acetaminophen (APAP) is a widely used analgesic and antipyretic drug. Drug-induced liver injury from agents such as APAP is known to vary between individuals within a species. To avoid liver injury and ensure the proper use of pharmaceutical products, it is important to be able to predict such risks using genetic information. This study evaluated the use of quantitative real-time polymerase chain reaction (RT-qPCR) to identify mRNAs (carried in the blood of male ddY mice) capable of predicting susceptibility to APAPinduced hepatotoxicity. Screening was performed on samples obtained at $18 \mathrm{~h}$ after treatment from mice that had been orally treated with $500 \mathrm{mg} / \mathrm{kg}$ APAP. APAP-induced hepatotoxicity was seen in $60 \%$ of the mice, and the mortality rate was $12 \%$. Blood APAP concentration did not differ significantly between mice with and without APAP-induced hepatotoxicity. We compared blood mRNA expression levels between mice with (positive, serious or lethal injury) and without hepatotoxicity in the APAP-treated group. The transcript levels of interleukin-encoding loci $I l 1 \beta, I l 10$, and tumor necrosis factor $(T n f)$ were increased in the lethal injury group. Transcripts of the loci encoding transthyretin (Ttr) and metallothionein 1 (Mt1) showed increases in the liver injury group, while those of the glutathione peroxidase 3-encoding locus (Gpx3) were decreased. APAP hepatotoxicity was potentiated in fasted animals, although fasting did not appear to affect the level of expression of these genes. These results indicate that mRNA expression of Illß, Il10, Tnf, Ttr, Mt1, and Gpx3 in mouse blood may provide useful surrogate markers of APAP-induced hepatotoxicity.
\end{abstract}

Key words acetaminophen; hepatotoxicity; mRNA; quantitative real-time polymerase chain reaction (RTqPCR); mouse blood

Acetaminophen (APAP) is a widely available antipyretic and analgesic, but the compound also is the leading worldwide cause of drug overdose and acute liver failure. ${ }^{1)}$ In some cases, drug-induced pharmacological action has shown differential susceptibility in individual patients. Correspondingly, drug-induced toxicities, including hepatotoxicity and mortality, have been shown to exhibit differences among individuals, reflecting differences in individual drug-induced toxicological susceptibility. Multiple studies have reported on the mechanisms of APAP-induced hepatotoxicity, but these studies have yielded minimal information as to the nature of person-to-person differences in APAP hepatotoxicity. It would be invaluable to be able to predict individual differences in APAP-induced toxicity prior to APAP treatment; such information could be critical to preventing the occurrence of APAP toxicity during clinical pharmacotherapy. Currently, quantitative real-time polymerase chain reaction (RT-qPCR) has become the standard technique for measuring gene expression due to RT-qPCR's accuracy, sensitivity, specificity, reproducibility, and robustness. ${ }^{2-4)}$ We provide here the first report (to our knowledge) on the identification of mRNA predictors of APAP-induced hepatotoxicity in mouse blood using RT-qPCR.

\section{MATERIALS AND METHODS}

Animals and Chemicals Adult male 4-week-old ddY mice $(20-25 \mathrm{~g}$ each) were obtained from Japan SLC (Hamamatsu, Japan). The animals were maintained on a 12-h light/ dark cycle in a temperature- and humidity-controlled room. The experiments were conducted in accordance with the standards established by the Japanese Pharmacological Soci- ety. The animals were allowed free access to laboratory pellet chow (CE-2; CLEA Japan, Inc., Tokyo, Japan) and water before the experiments. APAP was purchased from Junsei Pharmaceutical Co., Ltd. (Nagano, Japan). Other drugs and reagents were purchased from Wako Pure Chemical Industries, Ltd. (Osaka, Japan) as the highest grade available. In preparation for administration, APAP was dissolved in saline at the time of use.

RNA Isolation and RT-qPCR Assay To permit correlation with the APAP toxicity, expression levels of mRNA were quantified by RT-qPCR. The animals were acclimated for $5-7 \mathrm{~d}$ prior to a pre-dose blood draw, and blood was drawn from the tail vein of each mouse into tubes containing $1 \mathrm{~mm}$ ethylenediaminetetraacetic acid (EDTA) as the anticoagulant; total RNA was isolated using ISOGEN reagent (Nippon Gene, Tokyo, Japan), and RNA concentrations were determined using a NanoDrop 1000 (Thermo Fisher Scientific, Inc., Waltham, MA, U.S.A.). From each sample, $0.1 \mu \mathrm{g}$ of total RNA was reverse transcribed into single-stranded cDNA using a ReverTra Ace kit (Toyobo, Osaka, Japan). Aliquots of the resulting cDNA preparations then were subjected to qPCR analysis using KOD SYBR ${ }^{\circledR}$ qPCR Mix (Toyobo). A 96-well Step-one Real-Time PCR System (Applied Biosystems, Carlsbad, CA, U.S.A.) was used to determine mRNA expression levels of the target genes. Each mRNA level was normalized against that of the glyceraldehyde-3-phosphate dehydrogenase (GAPDH)-encoding locus (GenBank Accession no. NM_001289726). The sequences of the 24 primer pairs used were obtained from the TaKaRa Perfect Real Time Primers (TaKaRa Bio, Shiga, Japan), genes were as indicated in Table 1 and primer sequences were listed in Supplementary data. 
Table 1. Descriptions of Selected Genes and Genes of Interest

\begin{tabular}{|c|c|c|c|}
\hline Gen symbol & Gen name & GenBank Acc. N & Gene function ${ }^{\text {reff }}$ \\
\hline $\operatorname{Bax}$ & BCL2-associated X protein Bcl2 & NM_007527.3 & Positive regulation of apoptosis ${ }^{16)}$ \\
\hline Bcl2 & B cell leukemia/lymphoma 2 & NM_009741.4 & Negative regulation of apoptosis ${ }^{17)}$ \\
\hline Cat & Catalase & NM_009804.2 & Detoxification of reactive oxygen species ${ }^{21)}$ \\
\hline$D b p$ & $\mathrm{D}$ site albumin promoter binding protein & NM_016974.3 & Circadian clock, Heterocyclic compound binding \\
\hline Gpx2 & Glutathione peroxidase 2 & NM_030677.2 & Antioxidative protective system (gastrointestinal) \\
\hline Gpx3 & Glutathione peroxidase 3 & NM_008161.3 & Antioxidative protective system (blood $>$ liver $)^{32)}$ \\
\hline Gstm1 & Glutathione $S$-transferase, mu 1 & NM_010358.5 & Antioxidative protective system \\
\hline Gstp1 & Glutathione $S$-transferase, pi 1 & NM_013541.1 & Antioxidative protective system \\
\hline Hmoxl & Heme oxygenase (decycling) 1 & NM_010442.2 & Heme catabolism, Antiinflammatory properties ${ }^{22)}$ \\
\hline Mt1 & Metallothionein 1 & NM_013602.3 & Mineral absorption, Detoxification ${ }^{30)}$ \\
\hline$N f e 2 l 2$ & Nuclear factor, erythroid derived 2, like 2 & NM_010902.3 & Oxidative stress-mediated transcription factor ${ }^{24-26)}$ \\
\hline Sodl & Superoxide dismutase 1 & NM_011434.1 & Destroying free superoxide radicals ${ }^{21)}$ \\
\hline$T t r$ & Transthyretin & NM_013697.5 & Transport proteins such as albumin or transferrin ${ }^{31)}$ \\
\hline Mapk8 & Mitogen-activated protein kinase 8 & NM_016700.4 & MAP kinase and JNK family ${ }^{23)}$ \\
\hline Aifm 1 & Apoptosis-inducing factor, mitochondrion-associated 1 & NM_012019.2 & Apoptosis-inducing factor ${ }^{18)}$ \\
\hline Becnl & Beclin 1 & NM_019584.3 & Regulation of autophagy ${ }^{20)}$ \\
\hline $\operatorname{Atg} 7$ & Autophagy-related protein 7 & NM_001253717.1 & Regulation of autophagy ${ }^{19)}$ \\
\hline $\operatorname{Tnf}$ & Tumor necrosis factor & NM_013693.2 & A monocyte-derived cytotoxin ${ }^{27)}$ \\
\hline Nos 2 & Nitric oxide synthase 2 & NM_010927.3 & Nitric oxide synthase, inducible is an enzyme \\
\hline Il6 & Interleukin 6 & NM_031168.1 & A pro-inflammatory cytokine ${ }^{29)}$ \\
\hline$I l 1 \beta$ & Interleukin 1 beta & NM_008361.3 & An important mediator of the inflammatory response $\mathrm{e}^{28)}$ \\
\hline Ptgs 1 & Prostaglandin-endoperoxide synthase 1 & NM_008969.3 & The key enzyme in prostaglandin biosynthesis (constitutive) \\
\hline Ptgs 2 & Prostaglandin-endoperoxide synthase 2 & NM_011198.3 & The key enzyme in prostaglandin biosynthesis (inducible) \\
\hline $1 l 10$ & Interleukin 10 & NM_010548.1 & An anti-inflammatory cytokine ${ }^{27,29)}$ \\
\hline
\end{tabular}

ref) Numbers correspond to bibliographic references in the text.

Table 2. Acetaminophen (APAP) Hepatotoxicity in ddY Mice

\begin{tabular}{|c|c|c|c|c|}
\hline \multirow{2}{*}{$\begin{array}{l}\text { Category of group } \\
\text { (Number) }\end{array}$} & AST & ALT & \multirow{2}{*}{$\begin{array}{l}\text { Plasma concentration of acetaminophen (APAP) } \\
\qquad(\mathrm{ng} / \mathrm{mL})\end{array}$} & \multirow{2}{*}{$\begin{array}{l}\text { Ratio } \\
(\%)\end{array}$} \\
\hline & \multicolumn{2}{|c|}{ (Karmen units) } & & \\
\hline Total (150) & $1358 \pm 275$ & $1499 \pm 365$ & $865 \pm 39$ & 100.00 \\
\hline Group A (55) & $110 \pm 4$ & $43 \pm 3$ & $974 \pm 54$ & 36.70 \\
\hline \multicolumn{5}{|c|}{ "Hepatotoxicity Negative" } \\
\hline Group B (95) & $2250 \pm 441$ & $2539 \pm 592$ & $789 \pm 55$ & 63.30 \\
\hline \multicolumn{5}{|l|}{ "Hepatotoxicity Positive" } \\
\hline L Group C (53) & $4596 \pm 803$ & $5175 \pm 1147$ & $797 \pm 101$ & 35.30 \\
\hline $\begin{array}{l}\text { "Serious Injury" } \\
\text { Group D (18) } \\
\text { "Lethal Injury" }\end{array}$ & None & None & None & 12.00 \\
\hline
\end{tabular}

Mice $(n=150)$ were treated with acetaminophen (APAP) by oral administration (p.o.) of APAP $(500 \mathrm{mg} / \mathrm{kg}$ in $10 \mathrm{~mL} / \mathrm{kg}$ saline) at $18: 00$, and blood was collected $18 \mathrm{~h}$ later for determination of serum activity of alanine aminotransferase (ALT) and aspartate aminotransferase (AST) using a colorimetric kit. Plasma concentration of APAP was measured using a HPLC system, as described in Materials and Methods. Data are expressed as the mean \pm standard error of the mean (S.E.M.).

The results of all assays were checked against melting curves in order to confirm the presence of single PCR products. At least two independent experiments were conducted and samples were assessed in (at least) triplicate in each experiment.

APAP Hepatotoxicity and Plasma Concentration Mice were given an oral administration per os (p.o.) of APAP $(500 \mathrm{mg} / \mathrm{kg}$ in $10 \mathrm{~mL} / \mathrm{kg}$ saline) at $18: 00$, and blood was collected $18 \mathrm{~h}$ later for determination of serum activity of alanine aminotransferase (ALT) and aspartate aminotransferase (AST) using a colorimetric kit (Wako) as indicated in our previous reports. ${ }^{5,6)}$ Plasma concentration of APAP was measured using a modification of the method of Hori et al. ${ }^{7)}$ Briefly, an aliquot $(100 \mu \mathrm{L})$ of plasma was diluted with an equal volume of $0.2 \mathrm{M}$ $\mathrm{Na}_{2} \mathrm{HPO}_{4}, 0.1 \mathrm{M}$ citric acid buffer ( $\mathrm{pH} 3.0$ ), and the mixture then was combined with $300 \mu \mathrm{L}$ of ethyl acetate. The resulting samples were centrifuged at $3000 \times \boldsymbol{g}$ for $5 \mathrm{~min}$ and the upper layer was retained and the lower layer was discarded. After the removal of solvents by evaporation under nitrogen gas, the sample was dissolved in $100 \mu \mathrm{L}$ of mobile phase (methanol: $1 \mathrm{~N}$ acetic acid at $70: 30, \mathrm{v} / \mathrm{v}$ ), and injected into a HPLC system consisting of an Alliance 2695 separation module (Waters, Milford, MA, U.S.A.). Flow rate was kept constant at $0.4 \mathrm{~mL} /$ min, and peaks were monitored at $254 \mathrm{~nm}$ for $10 \mathrm{~min}$. The concentration of APAP was calculated using an APAP standard curve.

Statistical Analysis Statistical analysis was performed by two-way ANOVA, followed by the Bonferroni test to compare among multiple groups. Data are expressed as the mean \pm standard error of the mean (S.E.M.). A $p$-value of less than 0.05 was considered to be significant. Statistical analyses 
were performed using Ekuseru-Toukei 2012 software (Social Survey Research Information Co., Ltd., Tokyo, Japan).

\section{RESULTS}

As shown in Table 2, APAP-treated mice $(n=150)$ exhibited approximately 10 and 30-fold increases in serum AST and ALT activities (respectively) compared to those observed before APAP treatment (AST: 125 $44 \mathrm{KU}$, ALT: $56 \pm 6 \mathrm{KU})$. Next, we categorized the APAP-treated mice $(n=150)$ into 4 groups (designated A to D). Group A was a non-hepatotoxicity group comprising animals for which AST and ALT levels were effectively unchanged compared to those obtained prior to APAP treatment (hepatotoxicity negative). Group B was a hepatotoxicity-positive group, comprising all animals that did not fall into Group A. Within Group B, animals exhibiting APAP-induced severe hepatotoxicity (evidenced as AST and ALT levels both exceeding $1500 \mathrm{KU}$; serious injury) were categorized as Group C, and Group D corresponded to animals who died during APAP treatment. Thus, 36.8\% of the mice (Group A) did not show APAP-induced hepatotoxicity; $12.0 \%$ of the mice exhibited mortality (Group D). Although the groups displayed differences in APAP-induced hepatotoxicity, plasma concentrations of APAP did not differ significantly among the groups.

We assessed the mRNA expression (in mouse blood) of a panel of 24 genes that are potential markers of APAP-induced hepatotoxicity. Specifically, we examined the mRNA expression using RT-qPCR, comparing among the different groups of APAP treatment mice. The expression of the 24 selected genes has been reported to indicate events related to APAPinduced hepatotoxicity, including oxidative stress, apoptosis, autophagy, and inflammation. We compared blood mRNA expression levels between mice with (Groups B, C or D) and without hepatotoxicity (Group A) in the APAP-treated group. As shown in Table 3, six of the 24 genes showed significant differences correlating with APAP-induced hepatotoxicity. Transcripts for genes encoding tumor necrosis factor (Tnf), interleukin (IL)-1 $\beta$ (Ill $\beta$ ), and IL-10 (Il10) were significantly increased in Group D compared to Group A. Transcripts for genes encoding transthyretin (Ttr) and metallothionein 1 (Mt1) showed significant increases in the liver injury groups (Groups B-D), but those for the gene encoding glutathione peroxidase
3 (Gpx3) were markedly decreased. These results indicate that mRNA expression of Tnf, Ill $\beta, I l 10, T t r, M t 1$, and Gpx3 in mouse blood may offer useful predictors of APAP-induced hepatotoxicity.

Since the earliest studies of APAP-associated toxicity, it has been reported that APAP-induced hepatotoxicity is potentiated in the fasted state. ${ }^{8,9)}$ As shown in Table 4, fasting of animals $(n=80)$ potentiated APAP-induced hepatotoxicity in all of our treatment groups. Indeed, among the fasted animals, there

Table 3. Relative Quantity Values of Transcript (Group A=1.000)

\begin{tabular}{|c|c|c|c|c|}
\hline Gen symbol & Group A & Group B & Group C & Group D \\
\hline $\operatorname{Bax}$ & $1.00 \pm 0.09$ & $0.88 \pm 0.05$ & $0.91 \pm 0.08$ & $0.98 \pm 0.13$ \\
\hline $\mathrm{Bcl} 2$ & $1.00 \pm 0.08$ & $1.18 \pm 0.08$ & $1.09 \pm 0.08$ & $1.20 \pm 0.07$ \\
\hline Cat & $1.00 \pm 0.11$ & $1.06 \pm 0.10$ & $1.02 \pm 0.17$ & $1.05 \pm 0.17$ \\
\hline$D b p$ & $1.00 \pm 0.13$ & $1.06 \pm 0.12$ & $1.02 \pm 0.11$ & $0.81 \pm 0.15$ \\
\hline Gpx2 & $1.00 \pm 0.08$ & $1.09 \pm 0.13$ & $1.13 \pm 0.19$ & $1.04 \pm 0.38$ \\
\hline Gpx3 & $1.00 \pm 0.28$ & $0.54 \pm 0.05^{*}$ & $0.52 \pm 0.07 *$ & $0.33 \pm 0.05 *$ \\
\hline Gstm 1 & $1.00 \pm 0.07$ & $1.11 \pm 0.09$ & $1.09 \pm 0.08$ & $1.07 \pm 0.11$ \\
\hline Gstp1 & $1.00 \pm 0.07$ & $1.09 \pm 0.06$ & $1.15 \pm 0.09$ & $1.29 \pm 0.17$ \\
\hline Hmox 1 & $1.00 \pm 0.12$ & $1.01 \pm 0.11$ & $1.03 \pm 0.15$ & $1.27 \pm 0.34$ \\
\hline Mt1 & $1.00 \pm 0.13$ & $1.58 \pm 0.19 *$ & $1.68 \pm 0.30 *$ & $1.85 \pm 0.47^{*}$ \\
\hline Nfe2l2 & $1.00 \pm 0.06$ & $1.10 \pm 0.05$ & $1.06 \pm 0.06$ & $1.14 \pm 0.12$ \\
\hline Sod1 & $1.00 \pm 0.09$ & $0.98 \pm 0.06$ & $0.98 \pm 0.06$ & $1.07 \pm 0.11$ \\
\hline Ttr & $1.00 \pm 0.13$ & $2.20 \pm 0.36^{*}$ & $2.03 \pm 0.50 *$ & $2.08 \pm 0.89 *$ \\
\hline Mapk 8 & $1.00 \pm 0.09$ & $1.00 \pm 0.06$ & $1.03 \pm 0.08$ & $1.13 \pm 0.16$ \\
\hline Aifm 1 & $1.00 \pm 0.15$ & $1.33 \pm 0.19$ & $1.15 \pm 0.16$ & $1.21 \pm 0.35$ \\
\hline Becn 1 & $1.00 \pm 0.08$ & $1.01 \pm 0.07$ & $0.98 \pm 0.06$ & $0.97 \pm 0.08$ \\
\hline $\operatorname{Atg} 7$ & $1.00 \pm 0.08$ & $0.96 \pm 0.07$ & $1.08 \pm 0.09$ & $1.16 \pm 0.16$ \\
\hline $\operatorname{Tnf}$ & $1.00 \pm 0.10$ & $1.26 \pm 0.10$ & $1.35 \pm 0.09$ & $1.43 \pm 0.28 *$ \\
\hline $\operatorname{Nos} 2$ & $1.00 \pm 0.14$ & $1.29 \pm 0.11$ & $1.22 \pm 0.15$ & $1.26 \pm 0.30$ \\
\hline Il6 & $1.00 \pm 0.15$ & $1.15 \pm 0.14$ & $0.97 \pm 0.13$ & $0.88 \pm 0.19$ \\
\hline$I l 1 \beta$ & $1.00 \pm 0.07$ & $1.03 \pm 0.08$ & $1.20 \pm 0.12$ & $1.47 \pm 0.27^{*}$ \\
\hline Ptgs 1 & $1.00 \pm 0.16$ & $1.07 \pm 0.11$ & $1.01 \pm 0.15$ & $1.04 \pm 0.16$ \\
\hline $\operatorname{Ptgs} 2$ & $1.00 \pm 0.09$ & $1.07 \pm 0.07$ & $1.11 \pm 0.11$ & $0.85 \pm 0.14$ \\
\hline 1110 & $1.00 \pm 0.08$ & $1.40 \pm 0.14$ & $1.42 \pm 0.19$ & $1.91 \pm 0.49^{*}$ \\
\hline
\end{tabular}

mRNA expression in mouse blood and categorization by APAP hepatotoxicity. The mRNA expression of 24 genes in mouse blood was quantified by RT-qPCR, as described in Materials and Methods. cDNA corresponding to the GAPDH-encoding transcript was used as the internal control of these real-time analyses. The results were calculated using the $\Delta \Delta \mathrm{Ct}$ method and are expressed as the ratio of candidate mRNA level in each APAP hepatotoxicity groups (A, B, C, or D) to that in the value of Group A. $* p<0.05 v s$. Group A. All experiments were performed in triplicate. Data are expressed as the mean \pm standard error of the mean (S.E.M.).

Table 4. Acetaminophen (APAP) Hepatotoxicity in ddY Mice (Fasted Group)

\begin{tabular}{|c|c|c|c|c|}
\hline \multirow{2}{*}{$\begin{array}{l}\text { Category of group } \\
\text { (Number) }\end{array}$} & AST & ALT & \multirow{2}{*}{$\begin{array}{l}\text { Plasma concentration of acetaminophen (APAP) } \\
\qquad(\mathrm{ng} / \mathrm{mL})\end{array}$} & \multirow{2}{*}{$\begin{array}{c}\text { Ratio } \\
(\%)\end{array}$} \\
\hline & \multicolumn{2}{|c|}{ (Karmen units) } & & \\
\hline Total (80) & $7791 \pm 725$ & $4478 \pm 549$ & $926 \pm 40$ & 100.00 \\
\hline Group A (0) & None & None & None & 0.00 \\
\hline \multicolumn{5}{|l|}{ "Hepatotoxicity Negative" } \\
\hline Group B (80) & $7791 \pm 725$ & $4478 \pm 549$ & $926 \pm 40$ & 100.00 \\
\hline \multicolumn{5}{|l|}{ "Hepatotoxicity Positive" } \\
\hline Group C (51) & $8360 \pm 723$ & $4805 \pm 567$ & $932 \pm 43$ & 63.80 \\
\hline \multicolumn{5}{|l|}{ "Serious Injury" } \\
\hline Group D (24) & None & None & None & 30.00 \\
\hline "Lethal Injury" & & & & \\
\hline
\end{tabular}

Mice $(n=80)$ were fasted overnight and treated with acetaminophen (APAP) by oral administration (p.o.) of APAP $(500 \mathrm{mg} / \mathrm{kg}$ in $10 \mathrm{~mL} / \mathrm{kg}$ saline) at $18: 00$, and blood was collected $18 \mathrm{~h}$ later for determination of serum activity of alanine aminotransferase (ALT) and aspartate aminotransferase (AST) using a colorimetric kit. Plasma concentration of APAP was measured using a HPLC system, as described in Materials and Methods. Data are expressed as the mean \pm standard error of the mean (S.E.M.). 


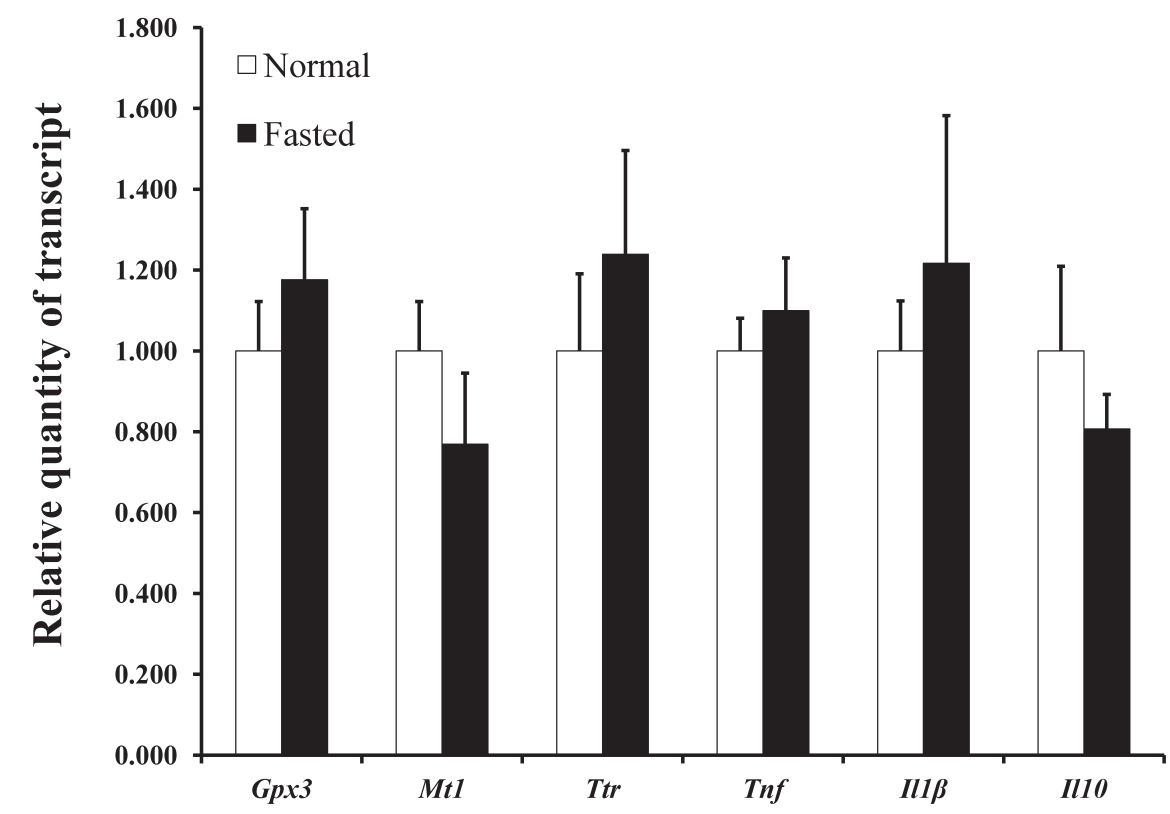

Fig. 1. Effect of Fasting on Mouse Blood mRNA Expression

The mRNA expression of 6 candidate marker genes (Gpx3, Mt1, Ttr, Tnf, Ill , or Ill0) in mouse blood was quantified by RT-qPCR, as described in Materials and Methods. cDNA corresponding to the GAPDH-encoding transcript was used as the internal control of these real-time analyses. The results were calculated using the $\Delta \Delta \mathrm{Ct}$ method and are expressed as the ratio of candidate mRNA level after fasting vs. that prior to fasting. All experiments were performed in triplicate. Data are expressed as the mean \pm standard error of the mean (S.E.M.).

were no hepatotoxicity-negative animals (Group A). As in the experiment described above, APAP plasma concentrations did not differ significantly among the response groups of fasted animals. We next compared the expression of the above 6 genes before and after fasting in mice. Notably, there was no significant the mRNA expression of these 6 genes between fasting and fed mice (Fig. 1).

\section{DISCUSSION}

Although APAP is generally considered to be safe at the usual therapeutic doses recommended by the manufacturer (1-4g/d), concerns have emerged over the past decade as APAP has been increasingly recognized as a major cause of acute liver failure in adults in the United States and many other countries worldwide. ${ }^{10-13)}$ Notably, 30 to $50 \%$ of cases of APAP hepatotoxicity admitted to hospitals nowadays result from a "therapeutic misadventure," wherein the daily dose may not have greatly exceeded the recommended safe limits but where specific risk factors are present. ${ }^{10,14,15)}$ Previously, it has been reported the APAP-induced hepatotoxicity correlates with various factors. The ingested dose of APAP seems to be the most important factor determining the development and severity of APAP hepatotoxicity. However, there have been few reports demonstrating the correlation of APAP-induced hepatotoxicity with genetic information using blood samples obtained before APAP treatment in the usual experimental models. Hence, the data reported here may inform the prevention of APAP-induced hepatotoxicity.

Oxidative stress and cell-death pathways (such as apoptosis and autophagy) have been implicated in APAP hepatotoxicity. Apoptosis-related factors such as Bcl-2, ${ }^{16)} \mathrm{Bax},{ }^{17)}$ and apoptosis-inducing factor (AIF) ${ }^{18)}$ and autophagy-related factors such as $\operatorname{Atg} 7^{19)}$ and beclin-1 ${ }^{20)}$ have been shown to play a role in APAP hepatotoxicity. Oxidative stress-related factors such as catalase, superoxide dismutase, ${ }^{21)}$ heme oxygenase-1 $(\mathrm{HO}-1){ }^{22)}$ and c-jun-N-terminal kinase $(\mathrm{JNK})^{23)}$ have been shown to mediate pathways critical to the induction of APAP hepatotoxicity. More recently, nuclear factor erythroid 2-related factor 2 ( $\mathrm{Nfe} 212$ or Nrf2) has been reported to affect APAP hepatotoxicity. ${ }^{24-26)} \mathrm{Nrf2}$ activity is regulated by protein level. In the present study, the levels of transcripts encoding these factors were not observed to correlate with different classes of hepatotoxicity (as defined by blood levels of liver enzymes). Our results suggest that expression of these genes in blood do not correlate with individual difference in APAP susceptibility in ddY mice.

As shown in Table 3, the gene expression of Thf, Ill $\beta$, and $I l 10$ were significantly increased only in Group D. The cytokines encoded by these genes have been implicated in the modulation of APAP hepatotoxicity. ${ }^{27-29)}$ We postulate that intrinsically higher mRNA expression in blood of the genes encoding these cytokines may predict the lethal effects resulting from APAP-induced hepatotoxicity. Saito et al. ${ }^{30}$ ) indicated that the induction of $M t 1$ by zinc chloride $\left(\mathrm{ZnCl}_{2}\right)$ did not affect the metabolic activation of APAP but attenuated the oxidant stress, such that $M t 1$ expression attenuated APAP hepatotoxicity. In contrast to that previous report, our data indicated that $M t 1$ expression was increased in animals exhibiting APAP hepatotoxicity. We propose a model as follows. Mt1 expression in liver cells is induced as a result of APAP hepatotoxicity, but $\mathrm{Mt1}$ expression in blood is not altered in response to APAP hepatotoxicity. Otherwise, original higher expression of Mt1 in blood was conversely increased and might be a marker of sensitivity to oxidative stress. Transthyretin (also called prealbumin) is a plasma protein produced in liver; decreases in transthyretin levels have been suggested (in early reports) to be indicative of impaired liver function following acute APAP toxicity. ${ }^{31)}$ Although the mechanisms are unclear, elevated levels of Ttr mRNA expression in blood could be a 
predictive factor for APAP hepatotoxicity. Glutathione peroxidase is a critical antioxidant enzyme employed in the detoxification of peroxides. Indeed, animals overexpressing Gpx3 have been reported to demonstrate dramatic resistance to APAP toxicity. ${ }^{32)}$ In the present study, the expression of Gpx3 was increased in the APAP hepatotoxicity-negative group and decreased in animals with elevated APAP hepatotoxicity; this data is consistent with the previous report.

As shown in Table 3, APAP-induced hepatotoxicity (as measured by blood levels of liver enzymes) was potentiated in fasted animals, but expression of the short-listed 6 genes was not significantly different in a comparison between fasted and fed animals (Fig. 1). Our results could reflect APAP hepatotoxicity in mice under normal conditions, where toxicity appears not to be affected by feeding conditions. Notably, the plasma concentration of APAP did not differ significantly among the response groups and did not appear to be affected by fasting. These data suggest that the susceptibility to APAP hepatotoxicity reflects inter-individual differences in gene expression rather than differences in plasma APAP concentration. In subsequent studies, we intend to test correlations between APAP hepatotoxicity and candidate gene expression, and those between APAP hepatotoxicity and plasma APAP concentrations.

In conclusion, our results indicate that mRNA levels of IL1 $\beta$, IL10, Tnf, Ttr, Mt1, and Gpx3 in mouse blood may offer useful predictors of APAP-induced hepatotoxicity. Confirmation of these results will require the accumulation of further data.

Acknowledgments This study was supported in part by a Grant-in-Aid for Scientific Research (C) (KAKENHI 25460220) from the Japan Society for the Promotion of Science, and by a Matching Fund Subsidy for Private Universities from the Ministry of Education, Culture, Sports, Science and Technology of Japan.

Conflict of Interest The authors declare no conflict of interest.

Supplementary Materials The online version of this article contains supplementary materials.

\section{REFERENCES}

1) Bunchorntavakul C, Reddy KR. Acetaminophen-related hepatotoxicity. Clin. Liver Dis., 17, 587-607, viii (2013).

2) Nolan T, Hands RE, Bustin SA. Quantification of mRNA using real-time RT-PCR. Nat. Protoc., 1, 1559-1582 (2006).

3) Derveaux S, Vandesompele J, Hellemans J. How to do successful gene expression analysis using real-time PCR. Methods, 50, $227-230$ (2010).

4) Schmittgen TD, Livak KJ. Analyzing real-time PCR data by the comparative C(T) method. Nat. Protoc., 3, 1101-1108 (2008).

5) Kanno S, Ishikawa M, Takayanagi M, Takayanagi Y, Sasaki K. Potentiation of acetaminophen hepatotoxicity and mortality by doxapram in mice. Biol. Pharm. Bull., 21, 934-937 (1998).

6) Kanno S, Tomizawa A, Hiura T, Osanai Y, Kakuta M, Kitajima Y, Koiwai K, Ohtake T, Ujibe M, Ishikawa M. Melatonin protects on toxicity by acetaminophen but not on pharmacological effects in mice. Biol. Pharm. Bull., 29, 472-476 (2006).

7) Hori Y, Iwasaki Y, Kuroki Y, Komiyayama Y, Nakatani H, Namera
A. Practical analysis of toxic substances useful for clinical toxicology-4-Acetaminophen. Chudoku Kenkyu, 15, 385-390 (2002).

8) Pessayre D, Dolder A, Artigou JY, Wandscheer JC, Descatoire V, Degott C, Benhamou JP. Effect of fasting on metabolite-mediated hepatotoxicity in the rat. Gastroenterology, 77, 264-271 (1979).

9) Walker RM, Massey TE, McElligott TF, Racz WJ. Acetaminophen toxicity in fed and fasted mice. Can. J. Physiol. Pharmacol., 60, 399-404 (1982).

10) Lee WM. Acetaminophen and the U.S. Acute Liver Failure Study Group: Lowering the risks of hepatic failure. Hepatology, 40, 6-9 (2004).

11) Ostapowicz G, Fontana RJ, Schiodt FV, Larson A, Davern TJ, Han SH, McCashland TM, Shakil AO, Hay JE, Hynan L, Crippin JS, Blei AT, Samuel G, Reisch J, Lee WM, U.S. Acute Liver Failure Study Group. Results of a prospective study of acute liver failure at 17 tertiary care centers in the United States. Ann. Intern. Med., 137, 947-954 (2002).

12) Ayonrinde OT, Phelps GJ, Hurley JC, Ayonrinde OA. Paracetamol overdose and hepatotoxicity at a regional Australian hospital: a 4-year experience. Intern. Med. J., 35, 655-660 (2005).

13) Cooper SC, Aldridge RC, Shah T, Webb K, Nightingale P, Paris S, Gunson BK, Mutimer DJ, Neuberger JM. Outcomes of liver transplantation for paracetamol (acetaminophen)-induced hepatic failure. Liver Transpl., 15, 1351-1357 (2009).

14) Larson AM, Polson J, Fontana RJ, Davern TJ, Lalani E, Hynan LS, Reisch JS, Schiodt FV, Ostapowicz G, Shakil AO, Lee WM, Acute Liver Failure Study Group. Acetaminophen-induced acute liver failure: results of a United States multicenter, prospective study. Hepatology, 42, 1364-1372 (2005).

15) Zimmerman HJ, Maddrey WC. Acetaminophen (paracetamol) hepatotoxicity with regular intake of alcohol: analysis of instances of therapeutic misadventure. Hepatology, 22, 767-773 (1995).

16) Adams ML, Pierce RH, Vail ME, White CC, Tonge RP, Kavanagh TJ, Fausto N, Nelson SD, Bruschi SA. Enhanced acetaminophen hepatotoxicity in transgenic mice overexpressing BCL-2. Mol. Pharmacol., 60, 907-915 (2001).

17) El-Hassan H, Anwar K, Macanas-Pirard P, Crabtree M, Chow SC, Johnson VL, Lee PC, Hinton RH, Price SC, Kass GE. Involvement of mitochondria in acetaminophen-induced apoptosis and hepatic injury: roles of cytochrome $c$, Bax, Bid, and caspases. Toxicol. Appl. Pharmacol., 191, 118-129 (2003).

18) Bajt ML, Ramachandran A, Yan HM, Lebofsky M, Farhood A, Lemasters JJ, Jaeschke H. Apoptosis-inducing factor modulates mitochondrial oxidant stress in acetaminophen hepatotoxicity. Toxicol. Sci., 122, 598-605 (2011).

19) Igusa $Y$, Yamashina S, Izumi K, Inami Y, Fukada H, Komatsu M, Tanaka K, Ikejima K, Watanabe S. Loss of autophagy promotes murine acetaminophen hepatotoxicity. J. Gastroenterol., 47, 433-443 (2012).

20) Dong D, Xu L, Han X, Qi Y, Xu Y, Yin L, Liu K, Peng J. Effects of the total saponins from Rosa laevigata Michx fruit against acetaminophen-induced liver damage in mice via induction of autophagy and suppression of inflammation and apoptosis. Molecules, 19, 7189-7206 (2014).

21) Kyle ME, Miccadei S, Nakae D, Farber JL. Superoxide dismutase and catalase protect cultured hepatocytes from the cytotoxicity of acetaminophen. Biochem. Biophys. Res. Commun., 149, 889-896 (1987).

22) Bauer I, Vollmar B, Jaeschke H, Rensing H, Kraemer T, Larsen $\mathrm{R}$, Bauer M. Transcriptional activation of heme oxygenase-1 and its functional significance in acetaminophen-induced hepatitis and hepatocellular injury in the rat. J. Hepatol., 33, 395-406 (2000).

23) Henderson NC, Pollock KJ, Frew J, Mackinnon AC, Flavell RA, Davis RJ, Sethi T, Simpson KJ. Critical role of c-jun (NH2) terminal kinase in paracetamol-induced acute liver failure. Gut, 56, 982-990 (2007). 
24) Rohrer PR, Rudraiah S, Goedken MJ, Manautou JE. Is nuclear factor erythroid 2-related factor 2 responsible for sex differences in susceptibility to acetaminophen-induced hepatotoxicity in mice? Drug Metab. Dispos., 42, 1663-1674 (2014).

25) Reisman SA, Csanaky IL, Aleksunes LM, Klaassen CD. Altered disposition of acetaminophen in Nrf2-null and Keap1-knockdown mice. Toxicol. Sci., 109, 31-40 (2009).

26) Yang JJ, Tao H, Huang C, Li J. Nuclear erythroid 2-related factor 2: a novel potential therapeutic target for liver fibrosis. Food Chem. Toxicol., 59, 421-427 (2013).

27) Gardner CR, Laskin JD, Dambach DM, Sacco M, Durham SK, Bruno MK, Cohen SD, Gordon MK, Gerecke DR, Zhou P, Laskin DL. Reduced hepatotoxicity of acetaminophen in mice lacking inducible nitric oxide synthase: potential role of tumor necrosis factor-alpha and interleukin-10. Toxicol. Appl. Pharmacol., 184, 27-36 (2002)

28) Williams CD, Farhood A, Jaeschke H. Role of caspase-1 and inter- leukin-1beta in acetaminophen-induced hepatic inflammation and liver injury. Toxicol. Appl. Pharmacol., 247, 169-178 (2010).

29) Bourdi M, Eiras DP, Holt MP, Webster MR, Reilly TP, Welch KD, Pohl LR. Role of IL-6 in an IL-10 and IL-4 double knockout mouse model uniquely susceptible to acetaminophen-induced liver injury. Chem. Res. Toxicol., 20, 208-216 (2007).

30) Saito C, Yan HM, Artigues A, Villar MT, Farhood A, Jaeschke H. Mechanism of protection by metallothionein against acetaminophen hepatotoxicity. Toxicol. Appl. Pharmacol., 242, 182-190 (2010).

31) Hutchinson DR, Smith MG, Parke DV. Prealbumin as an index of liver function after acute paracetamol poisoning. Lancet, 316, 121-123 (1980).

32) Mirochnitchenko O, Weisbrot-Lefkowitz M, Reuhl K, Chen L, Yang C, Inouye M. Acetaminophen toxicity. Opposite effects of two forms of glutathione peroxidase. J. Biol. Chem., 274, 10349-10355 (1999). 